\title{
Organization Appetite for Research: An Integrative Research Definition and Audit Framework to Evaluate Corporate Practice towards Research
}

\author{
Eman Reda Sabri \\ University of Northampton, Northampton, UK \\ Email: eman@richconsultancy-me.com
}

How to cite this paper: Sabri, E.R. (2019) Organization Appetite for Research: An Integrative Research Definition and Audit Framework to Evaluate Corporate Practice towards Research. Social Networking, 8, 85-103.

https://doi.org/10.4236/sn.2019.82006

Received: February 28, 2019

Accepted: April 25, 2019

Published: April 28, 2019

\section{Copyright $\odot 2019$ by author(s) and} Scientific Research Publishing Inc. This work is licensed under the Creative Commons Attribution International License (CC BY 4.0).

http://creativecommons.org/licenses/by/4.0/

\begin{abstract}
Organizational culture can be defined as the intermixture between values, visions, language, behaviors and beliefs that shape an entity's unique operating environment. Although the personality of a business may be difficult to articulate, it can have a huge impact on how members of an organization deal with each other, customers and other stakeholders. A good organizational structure facilitates attainment of objectives through proper coordination of all activities. Recently, practitioners and academics aim to identify type of culture before starting a project. Accepting and conducting research is a project by itself, in which, many organizations have a flexible appetite to conduct research to help their objectives. This paper demonstrates the identification of appropriate frameworks to prepare an audit of the organizational culture towards research informed decision-making and management, which means that the paper will analyze definitions of what research means before conducting the organizational research-culture audit to understand the research appetite of the organization.
\end{abstract}

\section{Keywords}

Organizational Culture, Personality, Corporate Practice

\section{Introduction}

Research is a very generic term for an activity that involves finding out things we did not know, or we want to prove/disprove. A more academic interpretation is that research consists of investigating data through analytic power to reach for findings [1]. Further, it is directly concerned with a distinct advancement of the 
frontiers of knowledge [2] while knowledge is a context and time independent [3]. This paper focuses on auditing organizational research culture, exploring the organization's appetite toward conducting a research.

However, presenting one description of "research" cited by author or researcher is not enough for the audit. Further knowledge is essential for business in a realistic phenomenon demanding distinct justifications and reasoning for stakeholders. Also, the search for knowledge in academia has many purposes as shown in Figure 1. However, search for knowledge practically in an organisational field could have additional meanings, and all these meanings will provide explanation and guidance for the experience [4]. For this reason, this report intends to delve on a process that analyses different definitions for the meaning of research which can then be practically recognised by practitioners as a simple paradigm to conduct research. A paradigm can be defined as the "basic belief system or world view that guides the investigation" ([5], p. 105). The basics of research meanings would be strategically coded, distinctly themed, and will subtract a single definition to be adopted in the activities of audit.

For this organization, a pseudonym will be used in the text so that the company cannot be recognized, and it will be referred to as (EK04). (EK04) is a holding PJSC private joint stock company registered in Abu Dhabi, United Arab Emirates. The principal activities of the group are developing, investing in and managing real estate properties.

The main question of this paper is trying to avail: Is EK04 flexible to conduct research? Therefore, the literature review will search for basics of meaning of research and also organizational culture auditing.

\section{Literature Review}

\subsection{Researcher Skills}

To define research, some traits were discussed in the literature. For instance, Swanson \& Holton [6] identified humility and scepticism as a fundamental trait the researcher must have. Additionally, Blanche, Durrheim, and Painter ([7], p. 19) argued that a researcher intended to gather appropriate findings must be

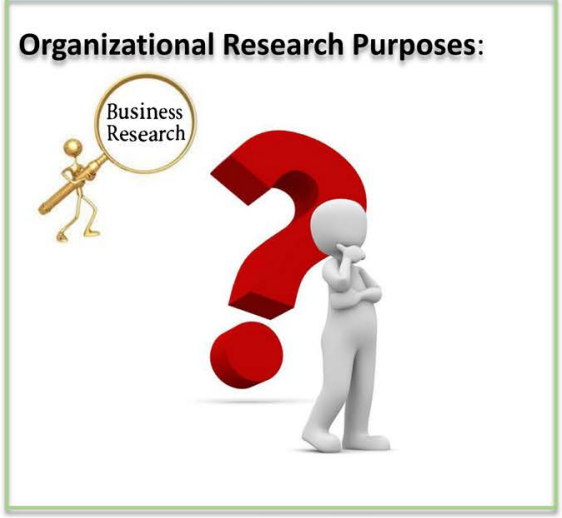

Academic Research Purposes:

(Walliman, 2011, pp8-9)

- Categorize

- Describe

- Explain

- Evaluate

- Compare

- Correlate

- Predict

- Control

Figure 1. Purpose of research process. 
in a position of reviewing previous work in the field, including a review of historical and oral materials available. Moreover, research can be only induced by careful-scientific investigations approach and skills [8]. All these basics appeared as fundamental skills required to do research.

\subsection{Research Aims \& Objectives}

After a successful identification of the skills, the second part is the identification of prevailing aims and objectives of the desired knowledge outcome. Weiss ([9], p. 381) showed that research has to have the knowledge with an indirect effect to influence decision making and policy deliberation. The same was reported by Stetler [10] that research knowledge aims to convince people and influence decision making. Roger ([11], p. 201) explained the innovative flow of research: giving knowledge, persuasion ability, making a decision, implementation, and confirmation. The implementation objective was partially discussed by Klein [12], who claims that research aims to affect strategy execution. On other hand, Swanson and Holton [6] observed that research is supposed to be inclusive of knowledge generation, problem-solving and reporting data.

\subsection{Research Process}

Avison et al. [13] stated that a research process is identified as an integration of theory and practice which is an indication of sourcing different evidence in supporting available findings. On other hand, Baskerville and Wood-Harper [14] suggested that a research process is inclusive of a Collaborative analysis, demanding participants to facilitate the searching action to form a theory, followed by collaborative action to change according to the results. The research process requires reviewing the literature which involves the process of identifying literature relevant to the topic of research, studying the literature and writing the review.

Interestingly, Blanche, Durrheim, and Painter ([7], p. 31) claim that a researcher must actively offer an excellent research practice after presenting the findings, precisely showing the ability to synthesise and integrate the overwhelmingly large volume of information on the topic under focus.

\subsection{Research Dissemination}

According to Roger [11], five aspects are required to a successful research implementation: Innovation, communication, time, social system and channel. These aspects if facilitated have a direct implication in supporting the researcher to disseminate results and findings.

\subsection{Organizational Culture Audit}

Organizational culture can be identified as a pattern of shared basic assumptions learned by a specific group. Further, it is inclusive of strategies put in place sufficiently for making considerations that are valid and as such teaching new mem- 
bers on the best strategy of perceiving, thinking and feelings ([15], p. 12). A more informal definition of organisational culture is the way things are done. Accordingly, later we can informally define research-culture audit as the way we deem research and actively engage in the process.

\section{Qualitative Approach}

To extract the most common understanding aiming to define what research means in the field place, a need to qualitatively analyse all definitions is essential. Nvivo can be used to code and subtract themes, however, in this paper, the text was manually coded with a different colour, and each colour addresses a theme of similar understanding or topic. Accordingly, the analysis revealed 8 themes showing as 8 different colors as in Figure 2.

From Figure 2, the yellow colours of Humility, Innovation, and Problem-solving was not a common topic that is popular. So, these three phrases will be excluded from the constructed research definition. The remaining colours will each have a theme/topic as an umbrella covering the related area of focus. Figure 3 presents the coded 8 themes for the research definitions.

\section{Research Meanings Finding}

The analysis of research definitions had coded major themes which are instrumental in assisting the process of constructing a single definition that can be used practically in the fields of organisations, enabling our project to conduct the research culture audit smoothly.

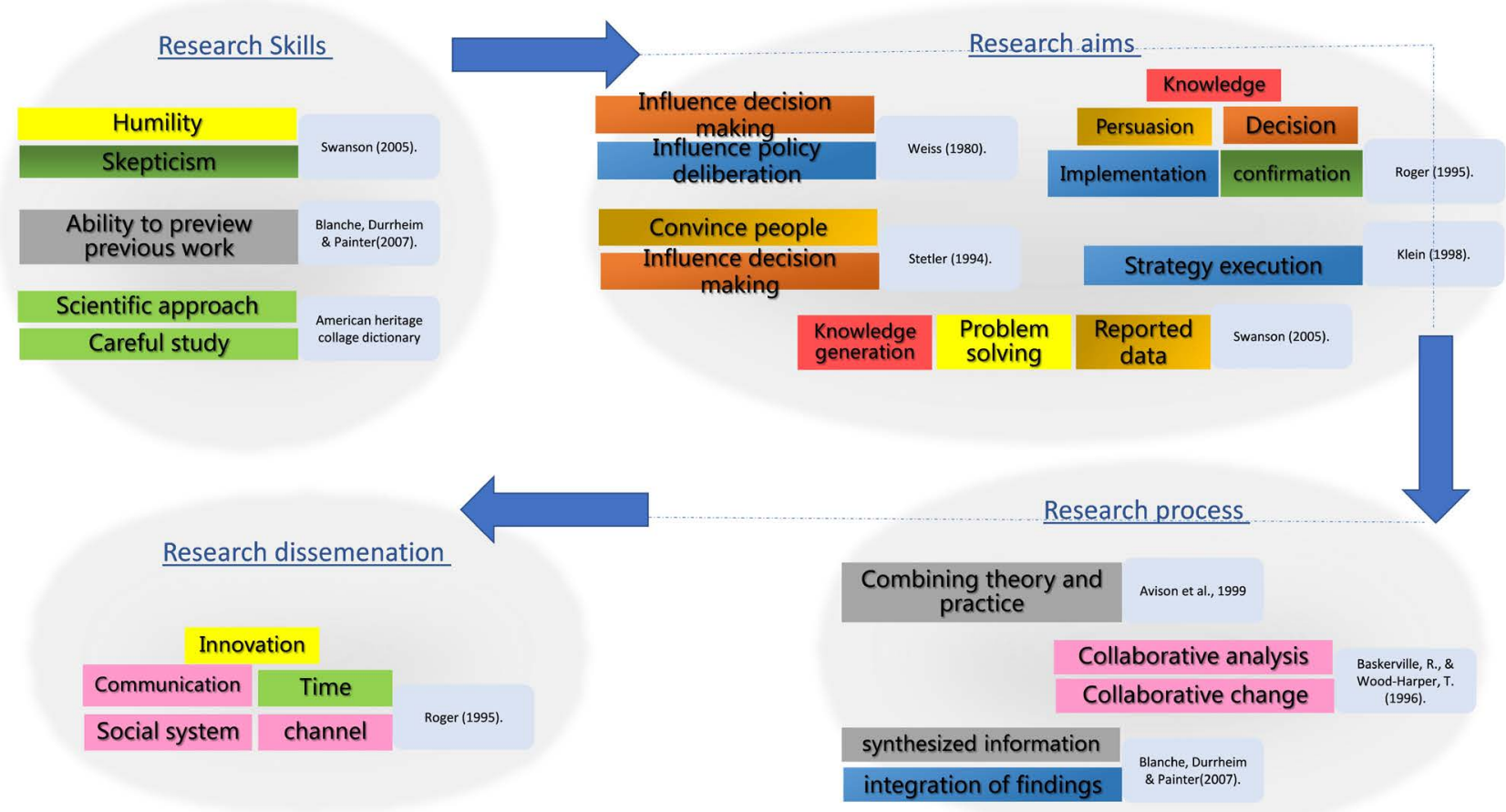

Figure 2. Integrative model of research meanings. 

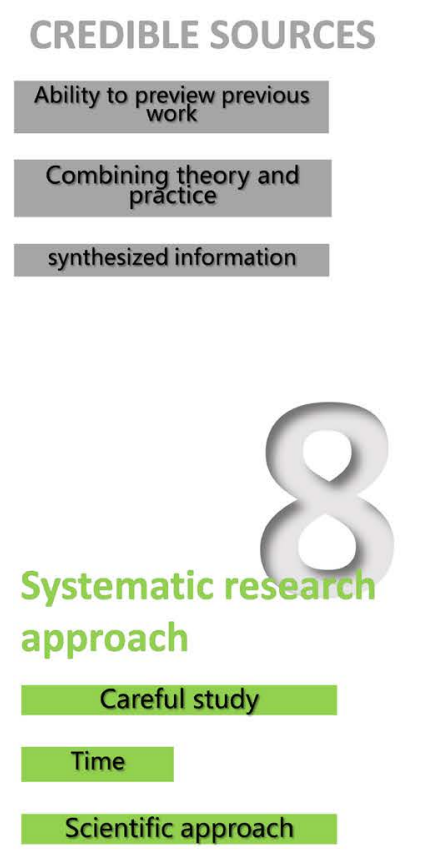

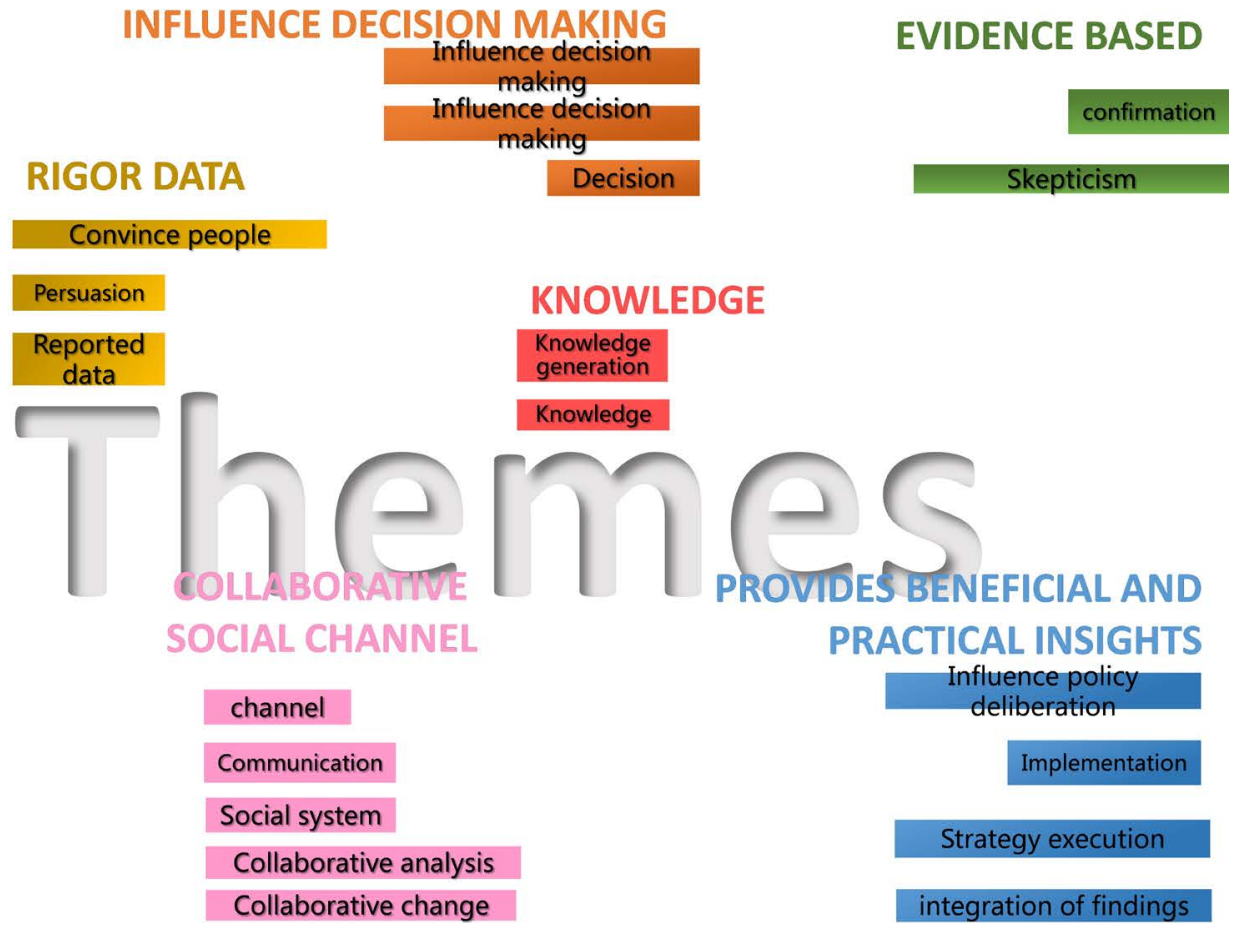

Figure 3. The coded 8 themes for research meanings.

The eight themes revealed eight aspects of research:

1) Careful study, scientific approach and time which all shows a purposeful technique toward establishing a research method. Highlighting on scientific approach and investigation, Malterud ([16], p. 483) explains it's a systematic standard, criteria, and checklist with guidelines.

2) Knowledge generation is the ultimate goal for research, and it shall add value to individuals and organisations. Tsoukas and Vladimirou ([17], p. 973) highlight knowledge in organisations as the individual capability to draw distinctions, within a domain of action, based on an appreciation of context or theory, or both.

3) Convincing people, the ability of persuasion and report data, falls under providing rigour information that can demonstrate an explanation with the truth behind all aspects related to the topic.

4) Having a trait of skepticism with the ability of confirmation, proves an evidence-based data, aims to provide a level of assurance that will improve findings [18].

5) Synthesized information, preview of previous work, and combining theory and practice are all a practice of using credible sources, which must use appropriate sources relevant to the topic [19], and Sources are trustworthy in their claims to the extent that they use reliable epistemic processes to produce the claims [20].

6) Repeatedly, decision making was mentioned three times. The influence of decision making providing a rigour knowledge is the goal of research in organisations. 
Collaborative CHANNEL

Channel, communication, social system, collaborative analysis and collaborative change are themes for a collaborative social channels that are required to implement findings.

PRACTICAL INSIGHTS Influence the policy deliberation, implementation, strategy execution and integration of finding, are a practice of providing beneficial and practical insights.

\section{DECISION MAKING}

Repeatedly this theme was clearly mentioned 3 times. Apparently, the influence of decision making providing a rigor knowledge is the goal of research in organizations.

CREDIBLE SOURCES Providing synthesized information, previewing previous work \& combining theory/practice, are a practice of appropriate sources, that are trustworthy \& reliable epistemic process
7) Influence policy deliberation, implementation, strategy execution and integration of finding, are a practice of providing beneficial and practical insights to the organisation's strategy.

8) Channel, communication, social system, collaborative analysis, and collaborative change are themes for a collaborative social channel that is required to implement findings.

Finally, being able to code significant themes of practical aspects of research, revealed one definition of research as: A systematic knowledge generation of rigour and evidenced data using reliable referencing, aimed at influencing the decision making and providing beneficial insights through collaborative social channels. Figure 4 present the constructed definition of research.

\section{Organizational Research Culture Audit}

\subsection{Audit Framework}

The selected framework is the Balanced Scorecard by Kaplan and Norton [21]. The framework will trace tangible and intangible assets through financial aspects, customer aspects, internal process, learning and growth aspects.

The most pertinent part for research culture audit is the learning and growth aspect which involves intangible "strategic readiness" [22], which are:

1) Human Capital: It is estimated by whether the employees have the right variety of skills and a suitable level of skills to complete the internal processes on the strategic map.

\section{Research Definition model}

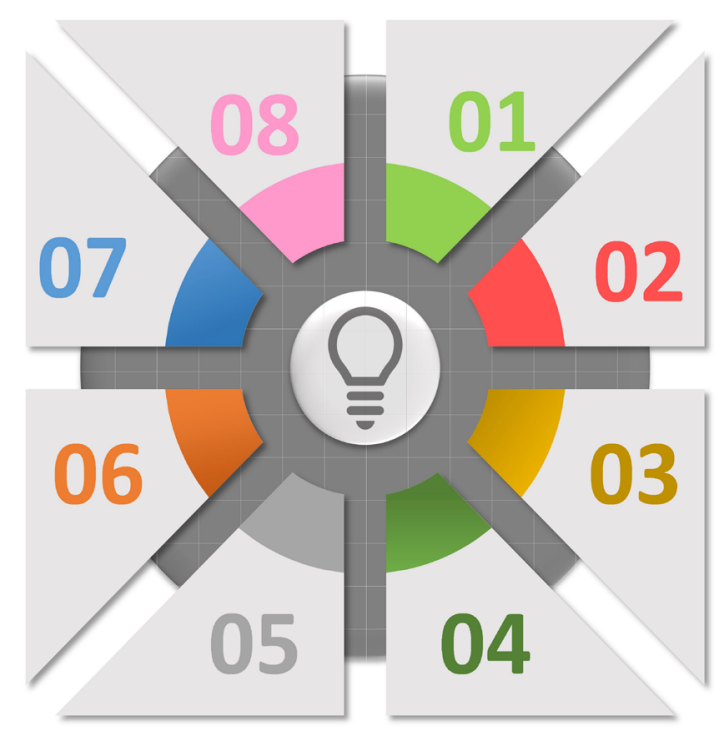

\section{SYSTEMATIC}

Careful study, scientific approach and time , shows a purposeful techniques toward research, applying a systematic standard of criteria, checklist with clear guidelines.

\section{KNOWLEDGE}

Knowledge and knowledge generation was twice clearly mentioned. It's the capability to draw distinctions, within am action, based on an appreciation of context or theory, or both.

\section{RIGOR DATA}

Convincing people, persuasion and report data, falls under providing rigor information that is able to demonstrate an explanation of truth behind all aspects related to the topic

\section{EVIDENCE BASED}

Having a trait of skepticism with the ability of confirmation, proves an evidence based data aims to provide a level of assurance that will improve the rigor knowledge and findings.

\section{A systematic knowledge generation of rigor and evidenced data using reliable referencing to influence decision making and provide beneficial insights through collaborative social channels.}

Figure 4. Consolidated research definition model. 
2) Information Capital: It is a measure of how well the company's strategic IT portfolio of infrastructure and applications support the internal processes.

3) Organisational Capital: It is measured through the alignment between the organisation's strategic objectives and the performance results of the internal processes.

These three particular aspects can identify the employee and leadership behaviour toward achieving the desired performance. Through the process, it is possible to identify the extent to which the organization's operations are systematic and the pattern adopted in collecting and reporting the different data and knowledge.

\subsection{Why Balanced Score Card (BSC)}

1) Certain intangibles are difficult for competitors to replicate. BSC can recognise intangible assets to identify the social framework and the communication channels required for research. Porter [23] claimed that relying solely on financial and tangible measures can promote a culture that sacrifices long-term value creation for short-term benefits.

2) It can give a comprehensive audit of all assets with the ability to select activities that match the unique strategic needs of an individual organization. BSC's audit can trigger all areas \& insights of strengths/weaknesses of the company [24].

3) The framework possesses the cause and effect factors, showing the systematic approach and its implementation in the organisation [25].

4) It aligns intangible assets to the company's strategy, helping to align the leadership \& decision-making aspect toward research. Huselid [26] investigated that human resource management has an impact upon financial results.

5) Recognise the plans for new future products [27]. BSC will define the circulation and flow of knowledge to achieve new competitive products.

6) The internal process of operation is dedicated, showing the medium between objectives and performance measure dimension [28].

To apply the benefits points of BSC on the constructed research definition, Figure 5 shows how the framework benefits match the definition.

And to better understand how BSC will audit the research culture based on the constructed research definition, Figure 6 demonstrates the relationship between the framework and the definition components, to facilitate the auditing.

The method that has been used for this audit in the organisation was similar to research done by Bremser and Barsky [29] who audited R \& D using the Balanced Scorecard of Kaplan and Norton [30]. The difference was the measurement of the R \& D metrics by Donnelly [31].

A systematic knowledge generation of rigor and evidenced data using reliable referencing to influence decision making and provide beneficial insights through collaborative social channels.

Figure 5. BSC framework benefits within research definition. 


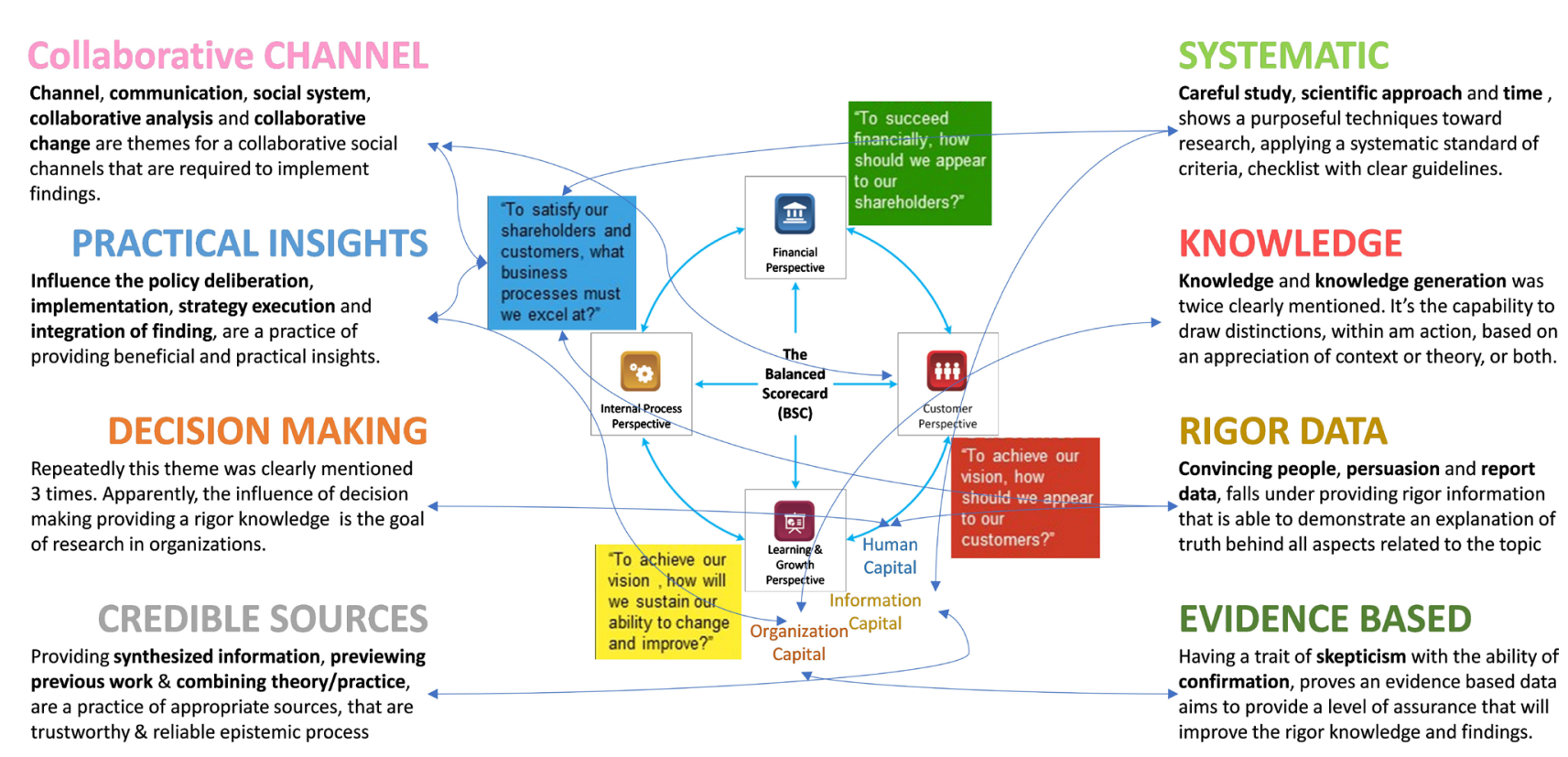

Figure 6. Relation between BSC framework \& research definition components.

\section{Audit Findings}

According to the selected audit framework of the Balanced Score Card [21], the collected data was arranged to answer certain perspectives about the organization, these perspectives guided by the Balanced Score Card have revealed the organizational culture of EK04 in general, and the research culture in particular.

\subsection{Vision, Mission, Strategy, and Values}

The organisation's vision, mission, strategy, and values were extracted from the organization's website, advertisements and other related press conferences, and have been concluded in Figure 7.

\subsection{Financial Objectives}

The strategy map is normally initiated from the financial goals, defining the stretch target, and allocating the growth and productivity factors of financial sub-objective measure, indicating cause and effect factors parameters. The organisation as a real estate competitive developer who is acting aggressively in the market, are aiming to dramatically increase sales for the purpose of their profitability and increased market share.

The stretch target is to increase net income by AED 1,000,000,000 by the next year. Accordingly, the sub-objectives for both productivity and growth are set too, which are; reduce development cost, increase revenue per sale and an increasing number of customers. Figure 8 shows the BSC financial map of EK04.

\subsection{Customers Perspectives}

Because revenue growth requires explicit attention to a target customer group, this audit, through the BSC framework, aim to understand how the organisation 


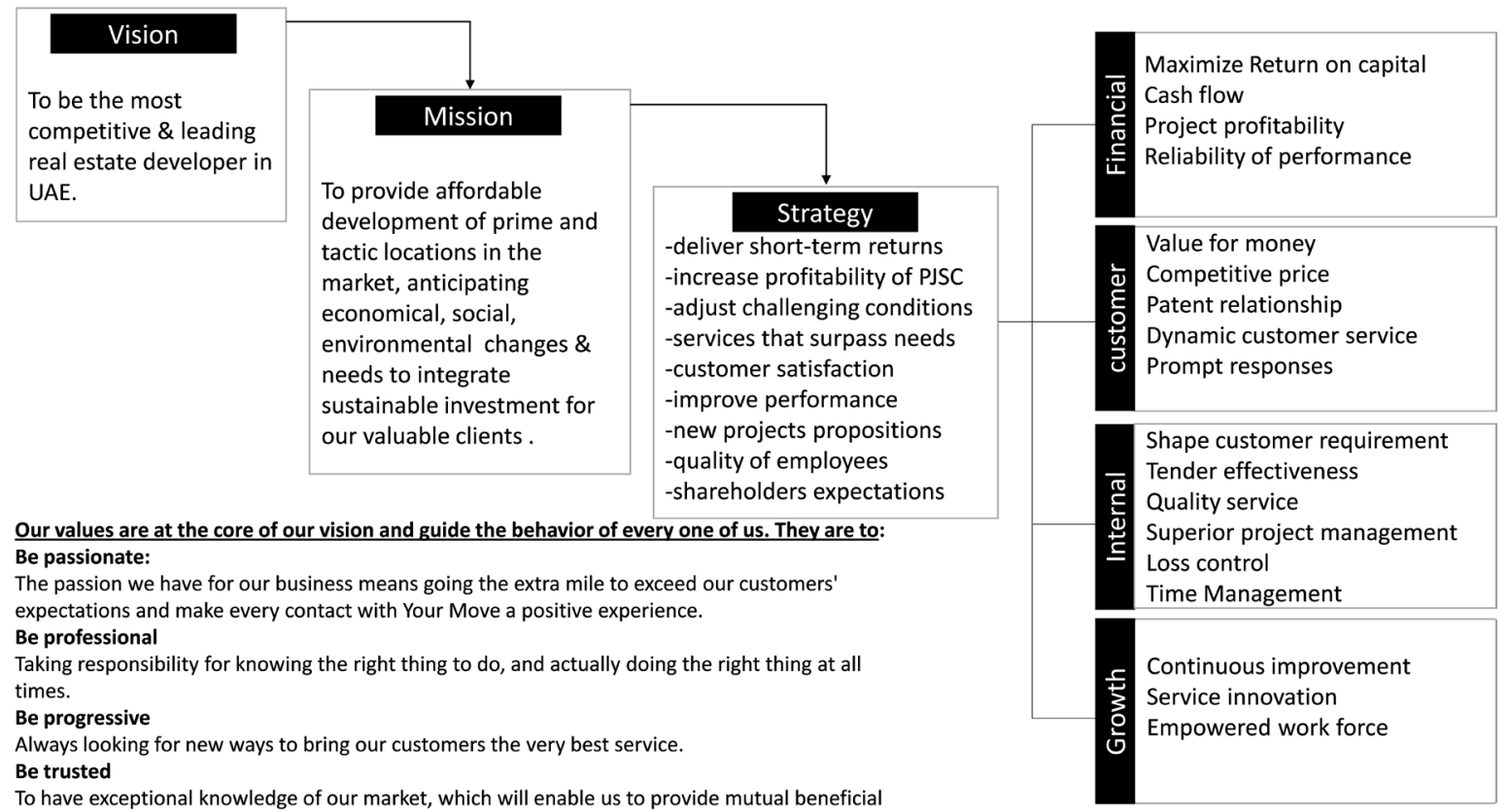

To have exceptional knowledge
relationship with our clients.

Figure 7. EK04's vision, mission, strategy and values.

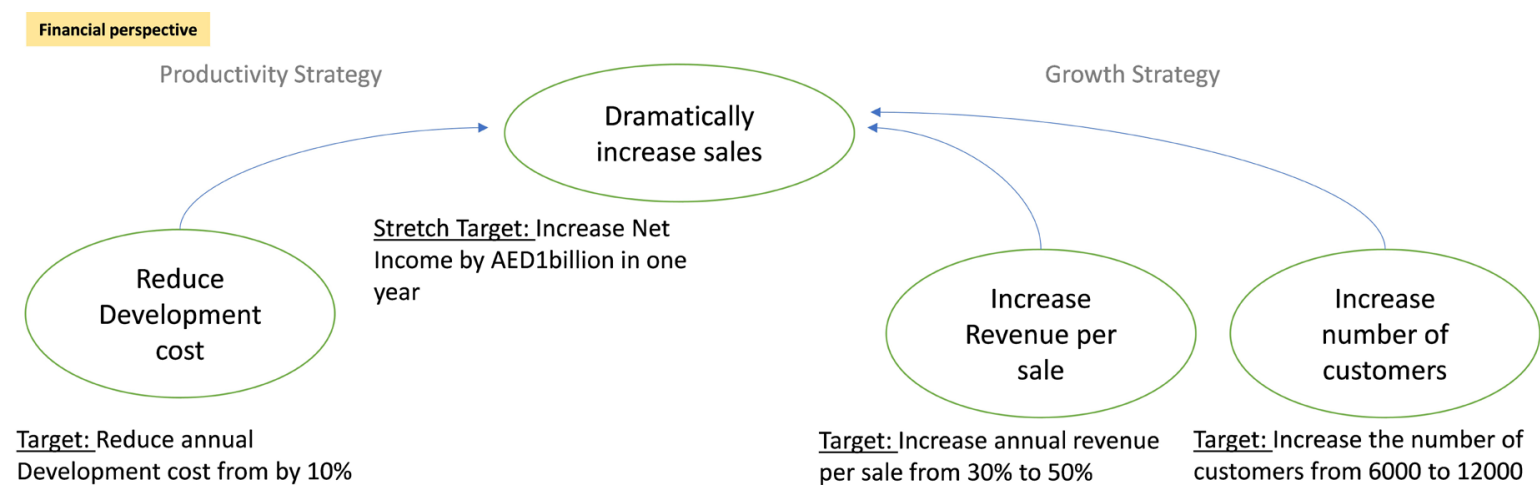

Figure 8. EK04's shareholders value.

embraces revenue growth target. This understanding will draw the attention to the culture of the company and how employees behave toward it.

A sister company of EK04 declared, as a significant shareholder, the importance of prime locations to Ek04. Prime locations can be considered as Quality of product. Going through EK04's Advertisements specially in the social media, it was clear that payment method facilitates instalment for five years without bank involvement, the customer can choose to come to the office, or a representative goes to customer, all documentation shall be provided at the same time, same place, providing customers a one-stop service for real estate investment.

The documentation itself appeared to be through a dedicated department. The customer service department is always mentioned in the announcements and advertisements. They provide all legalised documents to support the sales representative giving full service to the customer at a time. The organisation was eager to tender with big trusted and well-known companies like Drake \& Skull and 
ACC, Seeking for the thrilled image of excellent and trusted development [32].

Also, EK04 was found regularly participating in major real estate exhibitions, like, Cityscape Dubai, Cityscape Abu Dhabi, IPS, and ADHIX to stay in touch with customers and showcase products through a massive and top quality mock-up. This confirms the company is aiming to be a quality trusted developer presenting a selection of properties: residential and commercial plot lands in different sizes, buildings, apartments, villas. Figure 9 presents EK04's customer proposition and segmentation.

\subsection{Internal Perspectives}

The allocation of the process and target will enable everyone to achieve targets. The organisation can assess here whether the target in financial perspectives are possible or it's better to be lowered [21].

If financial goals are clear, everyone in the organisation should not be skeptical. Management can determine the level of performance; this can be done if financial targets get broken down into targets for internal processes and strategic themes and with specific time frames [29].

Apparently, from analysing TV interviews, EK04's operations are targeting to respond quicker to clients [33]. The company signed multi agreements obtaining big IT systems like ORACLE and Xerox [34] to accelerate the operation and response to clients. Also, this means they want to minimise the cost of errors and problem.

They employed more than hundred sales force among four cities in UAE [35], aiming to facilitate customers with available information about the projects.

EK04 has a presence on different channels: website, Facebook, Instagram. These channels are open to receive feedback and respond accordingly with every client. All advertisements have clear segmentation of the customers; it mentions "for Locals only".

Acquiring new projects and aiming to grow is evident in the press releases. A

Customer perspective

Quality 1 Price

\begin{tabular}{|l|l|l|}
\hline \multicolumn{2}{|l}{ Customer Segmentation } \\
\hline Segment & Primary & Secondary \\
\hline Local Emiratis & $\begin{array}{l}\text { Dubai, Abu Dhabi, Al-Ain, } \\
\text { Sharjah }\end{array}$ & Northern Emirates \\
\hline
\end{tabular}

\section{The Research Culture related questions for customers perspective:}

Questions about collaborative channels of Channel, communication, social system, collaborative analysis and collaborative change:

- Are there channels to facilitate communications and social system?

Figure 9. EK04's customer value proposition. 
spokesperson in 2018 explained that the strategy of the Company is to achieve continuous growth and to diversify its investments headed by real estate development projects.

The organisation looks very keen to sponsor and tie up with governmental institutions in exhibitions [36]. Another distinguished sponsorship was the Spanish football league tournament. Also, Part of CSR activities was the Red Crescent cooperation towards sponsoring 50 poor elderly in Abu Dhabi [37]. Figure 10 put down the internal perspective audit according to the BSC framework.

\subsection{Learning \& Growth Perspectives}

Learning and growth targets will clarify the readiness of the intangible assets of the company capital: Human, Information and organisation, and if it does function towards the strategic objectives.

Starting with the Human capital, assigned personnel should be responsible for each of the organisational target [21]. Accordingly, the information capital is determined for each of the human capital.

EK04 had established a standardized customer service centre that can operate and function appropriately with clients. The operation management seeks to achieve dynamic responses with customers. Based on previous perspectives, the organisation has a customer service department who can run the communication through a phone system supported by ORACLE software, aiming to minimize problems with respect to the human capital.

The organisation needs quality and qualified managers to run the operation according to the objectives. For this purpose, a need to check the qualifications of the senior managers, and if they fit the required responsibilities (LinkedIn profiles was used). The quality of the top managers can affect information of the company to be collected systematically and reported accordingly. For example, an IT specialist was hired holding master's degree, who is in charge of taking information from the communication channels and facilitate useful outputs to the company through running CRM programs, this program, on the other hand,
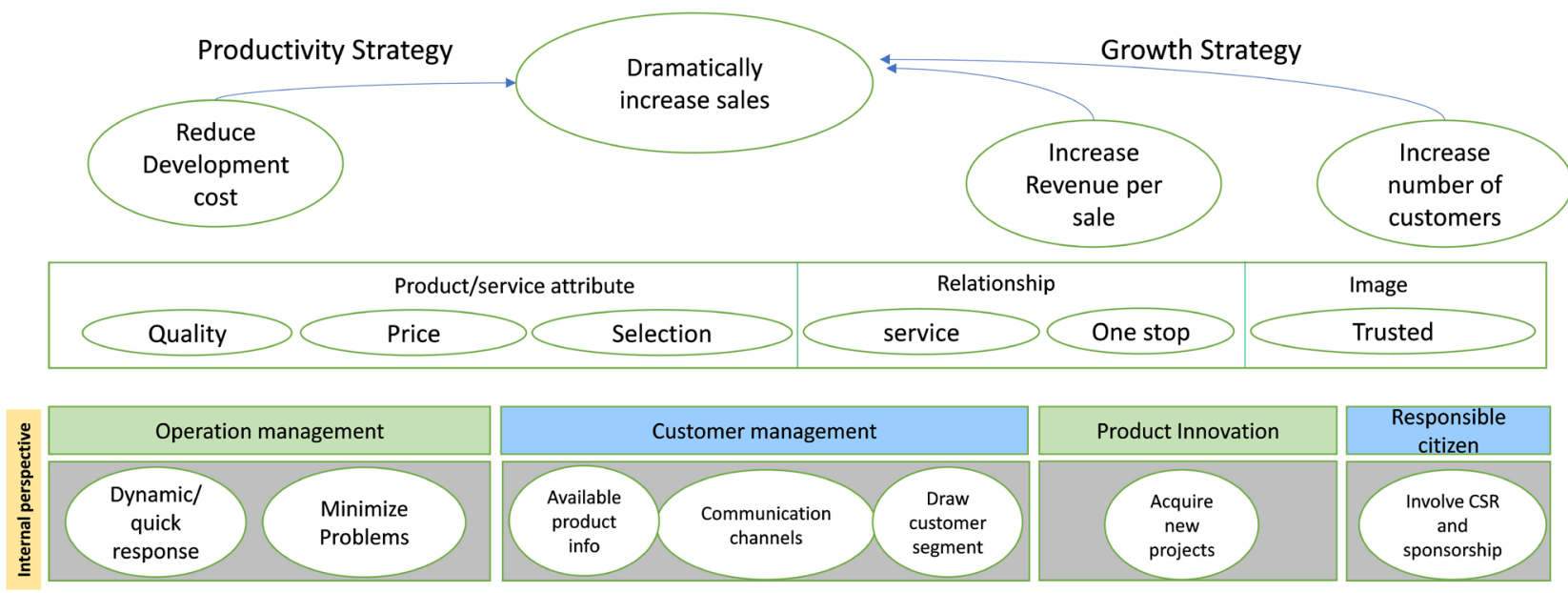

Figure 10. EK04's internet strategic themes. 
will provide better tactics to be used on digital channels. For example, the organisation hired marketing manager with ten years' experience in senior marketing management in UAE. The organisation shall be able to draw customer data and segmentation through marketing analyst, who would conduct useful marketing and data analysis.

The availability of information about the products was facilitated through the sales team and how sufficient they are in term of their number and their punctuality at work. EK04 has one headquartered office, supported with other four branches in different cities.

Regarding the organizational capital: culture, leadership, alignment and teamwork, EK04 shows a cultural objective of customer oriented and achieving results [35], and the leadership priorities are high in competency level [38].

The alignment objectives are to have HR policies to support strategies, which is clear and facilitated in Oracle system. The software does provide rigour system for punctuality, and also each employee has a set of targets, which if not accomplished in three months, the employee will receive a dismissal letter.

The teamwork objectives were clear in announcing the organisation's best practices. (EK04) celebrates annually with all branches in a five-star hotel in Dubai, announcing best results and awarding all employees with gold coins. Figure 11 add on learning and growth perspectives of EK04 through BSC framework.

\section{EK04’s Culture}

As a real estate developer focused on delivering objectives to stakeholders, EK04 overarching financial objectives is to provide dramatic sales amount. This primary objective is supported with three sub-objectives: reduce development cost, increase revenue per sale and an increasing number of customers. From the customer perspective, the company has an objective that customers continue to view it as a trusted developer who provides prime locations with competitive

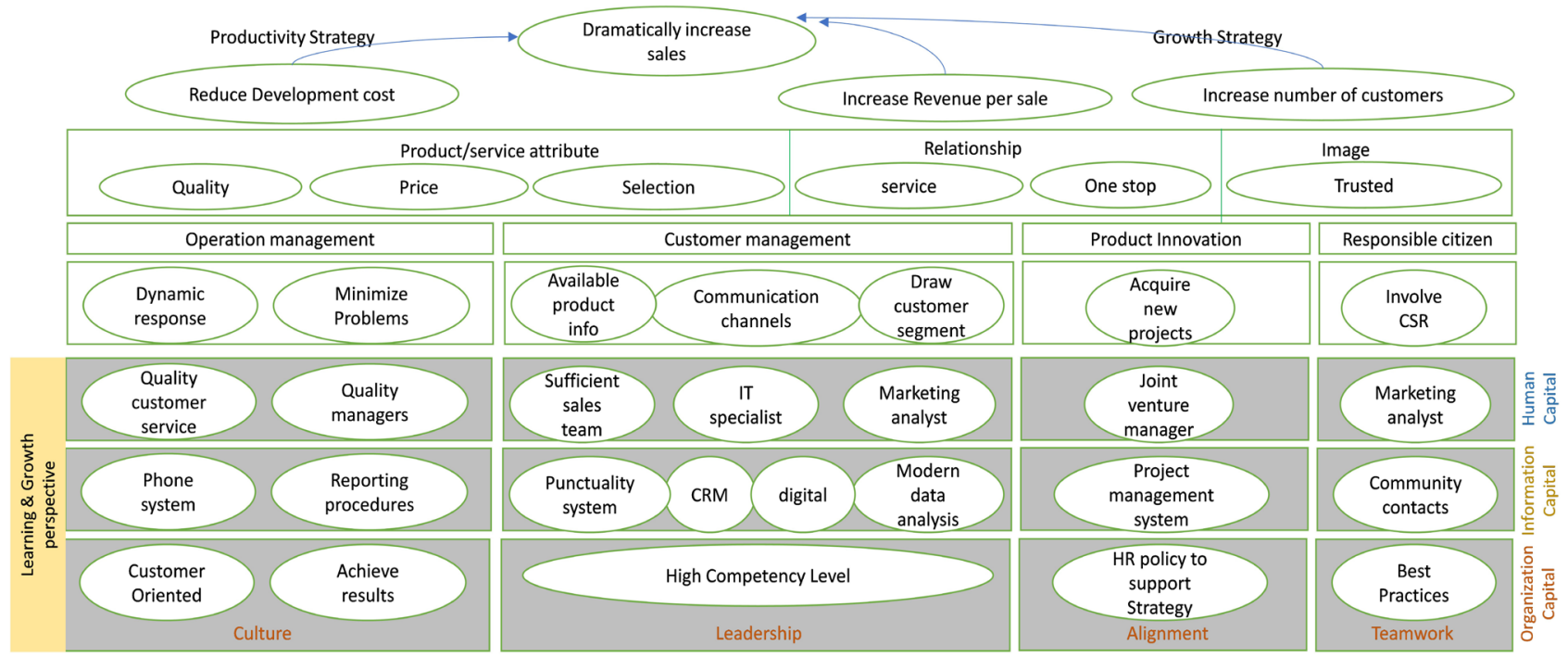

Figure 11. Creating strategic assets readiness. 
prices, giving various selections of master plans which customers can choose from. The strategy seeks to leverage this objective by creating a serviced one-stop station for investment.

EK04's internal process centres around four primary themes. The first focuses on the process needed to increase sales and revenue, supported with a robust system which can respond quickly to customers, at the same time, being able to minimize problems during the workflow.

The second internal theme emphasizes the fundamental customer management. The company can segment its targets, providing abundant information and communication channels to them. The company seems keen to be involved in the product innovation theme, by aiming to acquire new competitive projects as to be able to sustain in the market place. The last theme is evident in participating with CSR local events.

The company will foster employee's loyalty, productivity, and personal growth by engaging them in company's success, and by facilitating high-quality work environment and professional leaders who can take the appropriate decisions.

\section{EK04's Research Culture Result}

Each component of the constructed research model (Figure 4) was answered through the audit, giving a comprehensive overview (Figure 12) of what the research culture is in EK04. Findings of research definition themes are:

Systematic. Careful techniques are provided to maintain standards which are inclusive of Punctuality system, rigorous employment contract, dismiss conditions

\section{(EKO4) Research Culture model}

\section{Collaborative CHANNEL It is evident the company is involved proactively in many channels with customers, as well as internal communication between employees are provided through high-quality system}

PRACTICAL INSIGHTS The integration of finding throw modern data/ marketing analysis, working through project management system, delivering and celebrating best practices are all a practice of providing beneficial and practical insights.

DECISION MAKING Providing a rigor knowledge through clear customer segmentation, hiring qualified and professional decision makers and being determined to achieve results.

CREDIBLE SOURCES Providing synthesized information, is demonstrated in CRM practice to provide valid customers data which can provide authentic insights and directions to the operations.

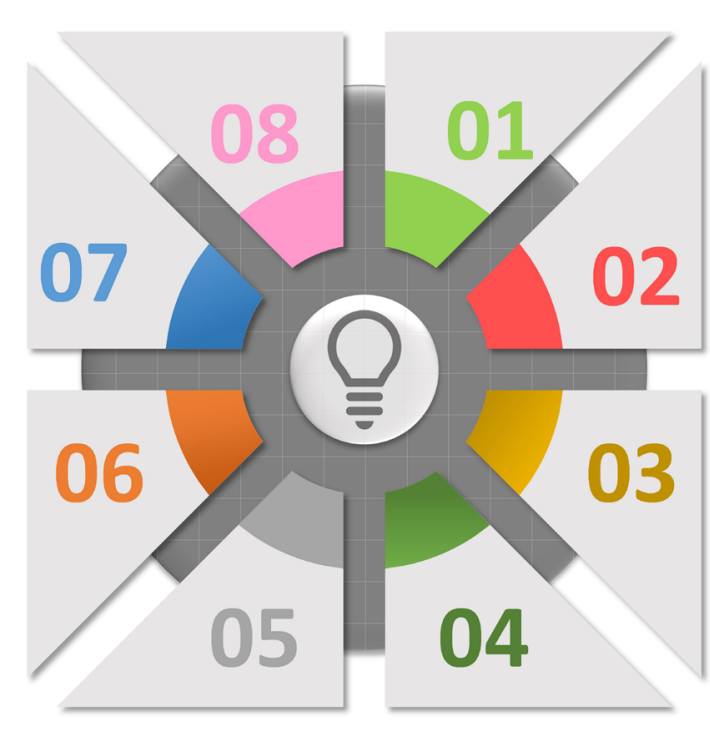

SYSTEMATIC

Careful techniques is provided to maintain standards. Punctuality system, rigorous employment contract, dismiss conditions and reporting procedures shows a systematic operation flow.

\section{KNOWLEDGE}

Knowledge is produced for aquiring larger market share, customer segmentation and analysis, competition and future new prime projects.

\section{RIGOR DATA}

Convincing people can be obtained by the establishment of quality customer service department, armed with all legal documents and able to clarify any issue.

\section{EVIDENCE BASED}

The alignment in HR policy to ensure supporting strategy shall avoid any skepticism of information and confirm certainty of procedures.

A systematic knowledge generation of rigor and evidenced data using reliable referencing to influence decision making and provide beneficial insights through collaborative social channels.

Figure 12. EK04's research culture model. 
and reporting procedures show a systematic operation flow.

Knowledge: Knowledge is produced for acquiring larger market share, customer segmentation and analysis, competition and future new prime projects.

Rigour data: Convincing people can be obtained by the establishment of a quality customer service department, armed with all legal documents and able to clarify any issue.

Evidenced-based: The alignment in HR policy to ensure supporting strategy shall avoid any skepticism of information and confirm the certainty of procedures.

Credible sources: Providing synthesized information is demonstrated in CRM practice to provide valid customers data which can give authentic insights and directions to the operations.

Decision making: Providing rigour knowledge through clear customer segmentation, hiring qualified and professional decision makers and being determined to achieve results.

Practical insights: The integration of finding throws modern data/ marketing analysis, working through the project management system, delivering and celebrating best practices are all practice of providing helpful and practical insights.

Collaborative channel: It is evident that the company is involved proactively in many channels with customers, as well as internal communication between employees that are provided through a high-quality system.

\section{Conclusion}

The organisation seems keen to control the market, and its culture appears to be driven by top-qualified leaders. The strategy map reaffirms competencies and skills required for the work-place. Knowledge appears essential through the systematic integration of findings and reporting. Leaders are geared to a performance of achievements. The organisation shows the trait of developing culture ([39], p. 30). The organisation's appetite towards research looks open and flexible, especially for subjects of gaining new customers. The audit confirms that the organisation has a systematic internal communication while collaborative work to change, using the rigour data acquired from leaders towards achieving explicit targets.

\section{Acknowledgements}

This audit was prepared based on secondary data. Some was available through the internet, and some other links was facilitated through the organization (EK04). Therefore, I would like to thank this organization for being supportive in reaching out for stock market links in a short time.

\section{Conflicts of Interest}

The author declares no conflicts of interest regarding the publication of this paper.

\section{References}

[1] Merriam, S.B. (1998) Qualitative Research and Case Study Applications in Educa- 
tion. Jossey-Bass, San Francisco.

[2] Coll, R.K. and Chapman, R. (2000) Choices of Methodology for Cooperative Education Researchers. Asia-Pacific Journal of Cooperative Education, 1, 1-8.

[3] Cousins, C. (2002) Getting to the "Truth": Issues in Contemporary Qualitative Research. Australian Journal of Adult Learning, 42, 192-204.

[4] Chen, C.P. (2001) On Exploring Meanings: Combining Humanistic and Career Psychology Theories in Counseling. Counseling Psychology Quarterly, 14, 317-331. https://doi.org/10.1080/09515070110091308

[5] Guba, E.G. and Lincoln, Y.S. (1994) Competing Paradigms in Qualitative Research. In: Denzin, N.K. and Lincoln, Y.S., Eds., Handbook of Qualitative Research, Sage, Thousand Oaks, 105-117.

[6] Swanson, R. and Holton, E. (2009) Research in Organizations: Foundations and Methods of Inquiry. Berrett-Koehler, Oakland.

[7] Blanche, M., Durrheim, K. and Painter, D. (2007) Research in Practice: Applied Methods for Social Science. University of Cape Town Press, Cape Town.

[8] Anon (2002) The American Heritage College Dictionary. 4th Edition.

[9] Weiss, G.H. (1980) Knowledge Creep and Decision Accretion. Knowledge: Creation, Diffusion, Utilization, 1, 381-404. https://doi.org/10.1177/107554708000100303

[10] Stetler, C.B. (1994) Refinement of the Stetler/Marram Model for Application of Research Findings to Practice. Nursing Outlook, 42, 15-25.

https://doi.org/10.1016/0029-6554(94)90067-1

[11] Roger, E.M. (1995) Diffusion of Innovations. The Free Press, New York.

[12] Klein, D.A. (1998) The Strategic Management of Intellectual Capital. Buttersworth, Boston. https://doi.org/10.1016/B978-0-7506-9850-4.50003-8

[13] Avison, D.E., Lau, F., Myers, M.D. and Nielsen, P.A. (1999) Action Research. Communications of the ACM, 42, 94-97. https://doi.org/10.1145/291469.291479

[14] Baskerville, R. and Wood-Harper, T. (1996) A Critical Perspective on Action Research as a Method for Information Systems Research. Journal of Information Technology, 11, 235-246. https://doi.org/10.1177/026839629601100305

[15] Schein, E.H. (1992) Organizational Culture and Leadership. 2nd Edition, Jossey Bass, San Francisco.

[16] Malterud, K. (2001) Qualitative Research: Standards, Challenges, and Guidelines. The Lancet, 358, 483-488. https://doi.org/10.1016/S0140-6736(01)05627-6

[17] Tsoukas, H. and Vladimirou, E. (2001) What Is Organizational Knowledge? Journal of Management Studies, 38, 973-993. https://doi.org/10.1111/1467-6486.00268

[18] Sellers, D., Schainker, L., Lockhart, P. and Yeh, H. (2017) Establishing a Common Language: The Meaning of Research-Based and Evidence-Based Programming (in the Human Sciences). Journal of Extension, 55, 6FEA2.

[19] Rempel, H., Buck, S. and Deitering, A.-M. (2013) Examining Student Research Choices and Processes in a Disintermediated Searching Environment. Portal: Libraries and the Academy, 13, 363-384. https://doi.org/10.1353/pla.2013.0036

[20] Chinn, C. and Rinehart, A. (2016) Commentary: Advances in Research on Sourcing-Source Credibility and Reliable Processes for Producing Knowledge Claims. Reading and Writing, 29, 1701-1717. https://doi.org/10.1007/s11145-016-9675-3

[21] Kaplan, R.S. and Norton, D.P. (2004) Strategy Maps: Converting Intangible Assets into Tangible Outcomes. Harvard Business School Press, Boston. 
[22] Perez, A. (n.d.) Measuring the Strategic Readiness of Intangible Assets. http://maaw.info/ArticleSummaries/ArtSumKaplanNorton04.htm

[23] Porter, M.E. (1992) Capital Disadvantage: America's Failing Capital Investment System. Harvard Business Review, 70, 65-82.

[24] Andersen, H., Lawrie, G. and Shulver, M. (2000) The Balanced Scorecard vs. the EFQM Business Excellence Model. 2GC Working Paper. http://www.2gc.co.uk

[25] Goulian, C. and Mersereau, A. (2000) Performance Measurement. Ivey Business Journal, 65, 48-53.

[26] Huselid, M.A. (1995) The Impact of Human Resource Management Practices on Turnover, Productivity, and Corporate Financial Performance. Academy of Management Journal, 38, 635-672. https://doi.org/10.2307/256741

[27] Wongrassamee, S., Gardiner, P.D. and Simmons, J.E.L. (2003) Performance Measurement Tools: The Balanced Scorecard and EFQM Excellence Model. Measuring Business Excellence, 7, 14-29. https://doi.org/10.1108/13683040310466690

[28] Hudson, M., Smart, A. and Bourne, M. (2001) Theory and Practice in SME Performance Measurement Systems. International Journal of Operations and Production Management, 21, 1096-1115. https://doi.org/10.1108/EUM0000000005587

[29] Bremser, W.G. and Barsky, N.P. (2004) Utilizing the Balanced Scorecard for R and D Performance Measurement. $R$ and D Management, 34, 229-238. https://doi.org/10.1111/j.1467-9310.2004.00335.x

[30] Kaplan, R.S. and Norton, D.P. (2001) Transforming the Balanced Scorecard from Performance Measurement to Strategic Management: Part II. Accounting Horizons, 15, 147-160. https://doi.org/10.2308/acch.2001.15.2.147

[31] Donnelly (2000) AP and L for R and D. CFO, The Magazine for Senior Financial Executives, 16, 44.

[32] Herald, M. (2018) DSI in Advanced Stages of Negotiation for AED 1 Billion Worth of Contracts with Wahat $\mathrm{Al}$ Zaweya in $\mathrm{Al}$ Ain, Mena Herald.

https://www.menaherald.com/en/economy/real-estate-construction/dsi-advanced-s tages-negotiation-aed-1-billion-worth-contracts-what

[33] Cityscape (2017). https://www.youtube.com/watch?v=o5TfF931X_M

[34] Core Experts Consulting (2018) Services Contract.

[35] Marasi News (2017) Wahat Al Zaweya Showcases Its Prime Projects at ADIHEX. https://www.youtube.com/watch?v=_tGNZLM4KJE

[36] (2018) 16th Edition of Abu Dhabi International Hunting and Equestrian Exhibition to Kick off Next Week. http://wam.ae/en/details/1395302708789

[37] (2018) ERC Branch in Abu Dhabi Receives Financial Donation to Support the Elderly. Emirates News Agency, 18 April. http://wam.ae/en/details/1395302682996

[38] Zoominof (2018). https://www.zoominfo.com/pic/wahat-al-zaweya-llc/348583976

[39] Fletcher, B. and Jones, F. (1992) Measuring Organizational Culture: The Cultural Audit. Managerial Auditing Journal, 7, 30-36. https://doi.org/10.1108/eb017606 


\section{Appendix}

Based on Figure 4 of research definition model, the audit questions for the (BSC) framework:

\section{Q1. Is the financial strategy clear in its target figures?}

Yes, and this will withdraw any scepticism towards working for the target.

Q2. For the need of research dissemination (Roger, 1995), are there channels to facilitate communications with customers?

Yes, the company seems to be very active on social media channels (Facebook, Instagram) as well as the free customer telecom (800EK04).

\section{Q3. Does the company facilitate collaborative analysis?}

This question shall be next evidenced in the human capital aspect.

\section{Q4. Is there a collaborative change toward enhancements?}

Once the communication channels are set and ready, the collaborative change can be processed and rectified according to it.

\section{Q5. Can the company's operation influence the policy deliberation?}

As long as the company is customer oriented, targeting to satisfy clients, either by responses or providing sufficient information, together with an aim to reduce the errors, it means the policy deliberation is flexible with the operation aspect as long as the customer is satisfied.

\section{Q6. How severe the implementation is?}

In terms of customer management, looks very difficult. Because being a customer-oriented means following customers trends which means keeping an eye on competition offers and what's new in the market.

\section{Q7. How can we describe the strategy execution?}

It is well organised towards achieving targets.

\section{Q8. Can findings be easily integrated?}

Seems the company has an open heart towards. Meaning, if finding is related to customers, then it can be easily integrated.

\section{Q9. Does the company require a careful and scientific approach?}

To acquire new competitive projects in prime locations that the company can sell with instalments, this needs a careful study, also, to minimise the errors and problems it requires a systematic and valid approach showing KPI's and measures to avoid problems according to it.

\section{Q10. Is time a valuable component for the company?}

Yes. Being able to segment customers, giving abundant information with quick responses and at the same time looking to acquire new project to sustain in the market, all indicate the Time factor importance.

Q11. For the need of the research process, are analysis conducted individually or any collaborative work required?

Will answer this question later during the Human capital in the learning and 
growth aspect.

Q12. Does it look like any collaborative change taking part in the company?

Yes. The operations indicate many departments are involved towards direct target accomplishment.

Q13. Could scepticism be developed during the internal process of the company?

The company as PJSC has explicit financial strategy map; this will support employees to recognise missions and targets without any scepticism.

Q14. How confirmation can be obtained?

ORACLE system will help managers to attain confirmation needed.

Q15. How the information during the internal process towards the learning \& growth can be synthesised?

There is a clear link of human capital, linking the objectives with the information capital, demonstrated with the high-quality IT system.

Q16. Would leaders require previewing previous work for each project?

It is not evident that manger requires previous work. However, the IT system can demonstrate analysis related to the time. Which means the infrastructure for this question is available.

\section{Q17. Does the company require combining theory with practice?}

Not confirmed. However, back to the explanation of how theory combined with practice (Avison et al., 1999) by providing evidence to the findings, seems the company is weaponed with all tools enabling employees to provide sufficient and credible analysis and findings.

Q18. How the culture, leadership, alignment, and teamwork affect the policy deliberation?

As long as the company celebrates best practices, giving away valuable rewards, it means the alignment between strategy and performance is substantial, together with leadership determining to achieve targets and be an influence to the policy deliberation.

\section{Q19. How severe the implementation in the growth objective?}

The operation seems indulged with facilitated systems. However, the financial set target is high, implementing growth is difficult and challenging.

Q20. How can we describe the strategy execution?

The human capital recruited comprises a bridge between a rigour and challenging objectives, and between the information and growth capital to sustain and improve the company. The strategy is solid, explicit and has a clear road map.

Q21. In which area/part the company does the integration of finding?

Results show the integration is implemented in the organisational capital-the growth component.

Q22. Is the Human capital able to make decisions?

Yes, human capital recruited is qualified with long work experience. 
Q23. Is the human capital qualified to persuade and convince about their projects?

Yes.

Q24. Does the information capital require reporting procedures?

Yes.

Q25. Is Knowledge an essential factor the information and organisational capital?

The objectives to acquire larger market share, customer segmentation and analysis, competition and future new prime projects are a variable that needs knowledge constantly.

Q26. For the need of research process, are analysis conducted individually or any collaborative work required?

The company found established with the proper department and employees. Each department has a manager who leads the flow between the team. This indicates no individuals work are taking place, work has to be collaborated. 